\title{
Determinants of behavioral intentions to use mobile healthcare applications in Jordan
}

\section{Nawras M. Nusairat ${ }^{a^{*}}$, Hadeel Abdellatif ${ }^{b}$, Jassim Ahmad Al-Gasawneh ${ }^{a}$, Abdel Hakim O. Akhors- haideh $^{c}$, Abdalrazzaq Aloqool ${ }^{\mathrm{a}}$, Saja Rabah ${ }^{\mathrm{a}}$ and Alaeddin Mohammad Khalaf Ahmad ${ }^{\mathrm{d}}$}

${ }^{a}$ Department of Marketing, Applied Science Private University, Amman, Jordan

${ }^{b}$ Department of Business Administration, Applied Science Private University, Amman, Jordan

${ }^{c}$ Department of Public Administration, University of Jordan, Amman, Jordan

${ }^{d}$ Department of e-Marketing and Social media, Princess Sumaya University for Technology, Amman, Jordan

\section{H R O N I C L E \\ A B S T R A C T}

Article history:

Received: May 10, 2021

Received in revised format: June

30, 2021

Accepted: August 26, 2021

Available online: August 26, 2021

Keywords:

Mobile healthcare

Behavioral intentions

Technology Acceptance Model
The purpose of this study is to examine the determinants of behavioral intentions to use of mobile health (m-Health) applications in Jordan through examining the mediating role of perceived trust and its influence on the behavioral intention to use such applications. A conceptual model was developed based on the extant literature. A questionnaire survey was administered to a convenient sample of 318. Data was analyzed using smart PLS 3. The findings suggest that patients' behavioral intentions to use m-Health applications are positively affected by perceived ease of use, perceived security, social influence and perceived trust of these applications. Perceived Trust was also found to mediate the relationship between these factors and the behavioral intention. Discussion, conclusions, implications, research limitations and areas for future research are also provided.

\section{Introduction}

Since the introduction of mobile technology in the 1950s, the world has witnessed an accelerated growth of the demand for this technology and since the 1990s the demand has exploded (Dunnewijk Hulten, 2007; Al-Hazmi, 2021; Bolarinwa, 2015). In just a couple of decades, mobile phones have exceptionally progressed from a mere idea of integrating telephony and computers to a smart product that is extensively used in every aspect of daily life (Lee et al., 2013). Nowadays, smartphones are equipped with high quality imaging, high-resolution touchscreens, video streaming, GPS navigation, e-mail, high speed internet access and many more. Recent statistics reveal that the number of smartphone users are projected to be 5 billion by 2025 and the average number of daily touches is a staggering 2617 times with more than 500 minutes of usage per day (Carmi et al., 2020). With this excessive use, smartphones are now being used beyond convenience, entertainment and fun to a variety of purposes with just a swipe of a finger or a touch of a button, ranging from browsing the internet to watching news, online banking, online learning and training, online shopping and most recently mobile Health care (m-health). The idea of m-Health was first introduced in 2000 under the term of "Unwired e-med" (Laxminarayan and Istepanian, 2000; Meshram et al., 2020) referring to the advancements of telemedicine services from desktop platforms to wireless and mobile platforms (Tachakra et al., 2003). Since then, this field has witnessed tremendous growth supported by the vast technological advancements in smartphones, wearable and portable devices, mobile communication, satellite communication, cellular systems and cloud-

* Corresponding author.

E-mail address: $\underline{n}$ nserat $@$ asu.edu.jo (N. M. Nusairat)

(C) 2021 by the authors; licensee Growing Science, Canada. doi: $10.5267 /$ j.ijdns. 2021.8 .013 
based computing (Baig et al., 2014; Naseer Qureshi et al., 2020; Al-Gasawneh et al., 2020; Hammouri \& Abu-Shanab, 2020). Such technologies have coined the concept of m-health where it is defined nowadays as the delivery of health services facilitated by mobile devices, medical sensors, and mobile communication to deliver better health care services and to improve the performance of health workers (Lee et al., 2017; Yang \& Kovarik, 2019; Hammouri et al., 2020; Manyati \& Mutsau, 2020). Currently, m-Healthcare is considered as one of the biggest technological breakthroughs and is becoming a huge industry that is witnessing an accelerating growth rate with a 10\% annual growth rate (Baek et al., 2016; Istepanian \& AlAnzi, 2020; Hawamleh et al., 2020). M-Health has the potential to effectively facilitate and improve health care delivery once integrated into a healthcare system. Not only it has the capability to increase access to healthcare services but also to improve routine healthcare monitoring and notifications, promote patient engagement, collect clinical and managerial information, diagnose diseases, detect unusual medical information and treatment, and provide efficient and effective medical monitoring (Yang \& Kovarik, 2019; Meshram et al., 2020). Therefore, m-Health has been successfully adopted in many developed countries and is currently being adopted in an increasing number of developing countries. However, the adoption rate of m-Health in developing countries is not at the required pace despite its importance in such countries with dysfunctional public health system that is facing major challenges such as healthcare infrastructure deficiencies and scarcity of clinical resources (Latif et al., 2017; Eze et al., 2018). Many factors may contribute to the slow adoption rate of $\mathrm{m}$-Health in developing countries, including the acceptance of such technology and proper use by potential users (Zhao et al., 2017; Petersen et al., 2020).

Jordan is one of few developing countries which has a well-established healthcare system. It has become a leader in healthcare services in the region where huge investments are continuously being allocated to the healthcare sector. According to the World Bank, Jordan is ranked first among Arab countries in health tourism and fifth in the World (Fagih \& Jaradat, 2015). Moreover, during the last decade Jordanians have shown an increasing interest in health issues and healthy lifestyle (Nusairat et al., 2020a). However, the Jordanian healthcare sector is facing massive challenges such as; high blood pressure conditions, diabetes, increase of non-communicable diseases, heart conditions and obesity-related conditions among the population. In addition to the large and recurrent waves of refugees from Iraq and Syria and the uneven distribution of healthcare services where most of these services are concentrated in the big urban cities (Al-Jbour et al., 2013; Al-Gasawneh \& Al-Adamat, 2020; Lupieri, \& Doetter., 2020;). Thus, m-Health could be the solution to overcome these obstacles where healthcare services can be offered with minimum cost to rural population and medical monitoring and follow up can also be improved. However, the success of this attempt relies on the acceptance of mobile service including m-Health among the Jordanian society. To this end and motivated by the dearth of empirical research on the acceptance of $\mathrm{m}$-Health in developing countries especially in the Middle East region, this research paper investigates the determinants of behavioral intentions to the use of m-Health applications in Jordan through examining the mediating role of perceived trust and its influence on the behavioral intention to use such applications.

\section{Theoretical foundation and hypothesis development}

Technology acceptance theories have been widely used in the field of technological innovation and Information and Communication Technology (ICT) to investigate the factors that affect adoption rate, users' intentions, and actual usage. The Technology Acceptance Model (TAM) which was introduced in 1989 by Davis has been widely used to investigate the influence of external factors on internal attitudes and intentions. TAM argues that the use of a system is affected by two main factors named, perceived usefulness (PU) and perceived ease of use (PEOU). PU is defined as "the degree to which a person believes that using a particular system would enhance his or her job", while PEOU is defined as "the degree to which a person believes that using a particular system would be free of effort”. PU and PEOU form the individuals' attitude towards the technology and thus affects the actual system use. Therefore, any technology that has a more positive PU and PEOU will have higher chances of being accepted and used by potential users (Henderson and Divett 2003). A review of the extant literature on the acceptance of various IT technologies have strongly demonstrated that PU and PEOU widely influence individuals' perceptions to use a new technology (Hammouri et al., 2021a; Holden \& Karsh, 2010; Phan \& Daim, 2011; Sintonen \& Immonen 2013). In the context of m-Health, Lim (2011) found that the intention to use mobile application to seek health information was positively and significantly predicted by PU. Further, many studies indicate that PEOU and PU significantly influence patients' intention to adopt m-Health technology (Fagih and Jaradat, 2015; Zhao et al., 2017; ALsswey et al., 2018). Therefore, we construct the first two hypothesis as:

H1: There is a statistically significant positive effect for perceived usefulness on the behavioral intentions to use m-Health application.

H2: There is a statistically significant positive effect perceived ease of use on behavioral intention to use m-Health application.

Moreover, social influence (SI) which is defined as "the extent to which consumers perceive that important other such as family and friends believe they should use a particular technology" (Venkatesh et al, 2012) is found to be a key influential factor for the adoption and use of technology (Hoque \& Sorwar, 2016; Tavares \& Oliveira, 2018). As proposed by Diffusion of Innovation theory, the social system has a major impact on users' decisions to adopt a certain technology more than the characteristics of the technology itself (Hsu et al., 2004; Nusairat et al., 2021). In the context of m-Health several studies have indicated that social influence has a significant effect on the intention to use m-Health applications (Zhang et al., 2014; Miao et al., 2017; Aljohani \& Chandran, 2019). Thus, we hypothesize: 
H3: There is a statistically significant positive effect for social influence on behavioral intention to use m-Health applications.

Another key factor that influences the behavioral intention to use m-Health application is perceived security (PS). Patients are reluctant to share their information if they have fears that the service provider will share their personal information with third parties without their permission (Zhou, 2012; Petersen et al., 2020). Several studies have acknowledged that security issues are significantly critical for the acceptance and wide use of m-Health technologies (Sun et al., 2010; Fernandez-Aleman et al., 2013; Alloghani et al., 2015). Therefore, we hypothesize:

H4: There is a statistically significant positive effect for perceived security on behavioral intention to use $m$-Health applications.

Moreover, trust which is defined as "the belief that $m$-Health application has the characteristics required to function as anticipated in a given circumstances" (McKnight et al., 2011), is one of the most influential factors on the adoption of any kind of technology (Mohamed et al., 2011; Akter et al., 2013; Nusairat et al., 2020b). Trust is a critical factor in the relationship between users and any technology (Hammouri \& Abu-Shanab, 2017; Zhang et al., 2020). The popular principle "no trust, no use" will always be at the heart of designing any automated system (Schaefer et al., 2016). Within the extant literature, PU, PEOU, SI and PS have been found to positively impact perceived trust (PT) of any system. For instance, Lee and Jun (2007) claimed that in the context of mobile commerce, PU and PEOU are important predictors of users' trust. Similarly, Amin et al., (2014) have found that PU can have a significant positive influence on users' perceived trust of mobile websites. Most recently, Ventre and Kolbe (2020) reported the significance of PU on consumers' trust. Moreover, many studies claim that social influence will affect user's trust towards a system (Alsajjan and Dennis, 2010; Liébana-Cabanillas et al., 2014; Hammouri et al., 2021b). Other studies found that perceived security of any system can positively influence users' trust (Damghanian et al., 2016). Therefore, we hypothesize:

H5: There is a statistically significant positive effect for perceived usefulness on user perceived trust in mobile healthcare applications.

H6: There is a statistically significant positive effect perceived ease of use on user perceived trust in mobile healthcare applications.

$\mathbf{H}_{7}$ : There is a statistically significant positive effect for social influence on user perceived trust in mobile healthcare applications.

H8: There is a statistically significant positive effect for perceived security on user perceived trust in mobile healthcare applications.

In the context of m-Health, patients will use m-Health applications only if they are assured that these are functioning properly and delivering precise and reliable information. Several studies claim that trust has a direct or indirect mediation effect on users' intention to adopt or use new technology (Yoon, 2009; Shareef, 2011). Therefore, we hypothesize:

H9: There is a significant positive effect of trust on behavioral intention to use m-Health applications.

$\mathbf{H}_{10}$ : The relationship between perceived usefulness and user's behavioral intentions to use m-Health applications is mediated by perceived trust.

H11: The relationship between perceived ease of use and user's behavioral intentions to use m-Health applications is mediated by perceived trust.

$\mathbf{H}_{12}$ : The relationship between social influence and user's behavioral intentions to use m-Health applications is mediated by perceived trust.

H13: The relationship between perceived security and users' behavioral intentions to use m-Health applications is mediated by perceived trust.

\section{Methodology}

This study is descriptive, which is a type of research that can describe a phenomena or specific state while also depicting the current situation and enabling for a decision to be made. The objective of this type of research is to validate a previously developed hypothesis that is relevant to current events. The research population of this study comprised current users of mobile healthcare applications in Jordan. Self-handled questionnaire was developed to collect relevant data. Apart from the respondent demographic profile, the questionnaire was made up of 18 items, separated into seven parts. The first two parts measured each of perceived usefulness and perceived ease of use and was adapted from Davis et al. (1989), the third section was related to perceived security adapted from Puriwat and Tripopsakul (2017), the fourth was related social influence features adapted from (Mertins \& Austerm ann, 2014), the fifth section was about the mediating variable (perceived trust) borrowed from (Alkailani, 2016), and the sixth was about the dependent variable (behavioral intentions) adapted from Puriwat and Tripopsakul (2017). The questionnaire items were assessed using five point Likert scales. Given that the measures of the current study are borrowed from previously established research, measurement scales were deemed to be reliable and valid. 
However, the measures were further subjected to academic piloting. Data was collected over 6 weeks (February to April 2021) from a convenient sample of mobile healthcare application users in Jordan approached by email and through social media. The sample size should be in accordance with the power of analysis, which is the minimum number of respondents possible given the model's complexity. The minimal sample size for the present study was then identified as 74, based on Green's (1991) table and utilizing the five predictors from the research framework with a moderate impact size, as proposed by Gefen et al. (2011). Furthermore, according to Hair (2010), to obtain reliable results, the sample size must be greater than 100 . Therefore, 340 responses generated over six weeks of data collection was considered adequate for data analysis. Collected data was screened for completeness first and several 318 responses were then considered for analysis, with 22 questionnaires being eliminated due to being incomplete. Data analysis was carried out using Smart PLS-SEM software.

\section{Results}

\subsection{CFA model}

To assess the five first-order constructs in the study, 18 items were used (PU, PE, PS, SI, PT, BI). The study used confirmatory factor analysis to evaluate the research measurement model. Fig. 1 depicts the measurement model.

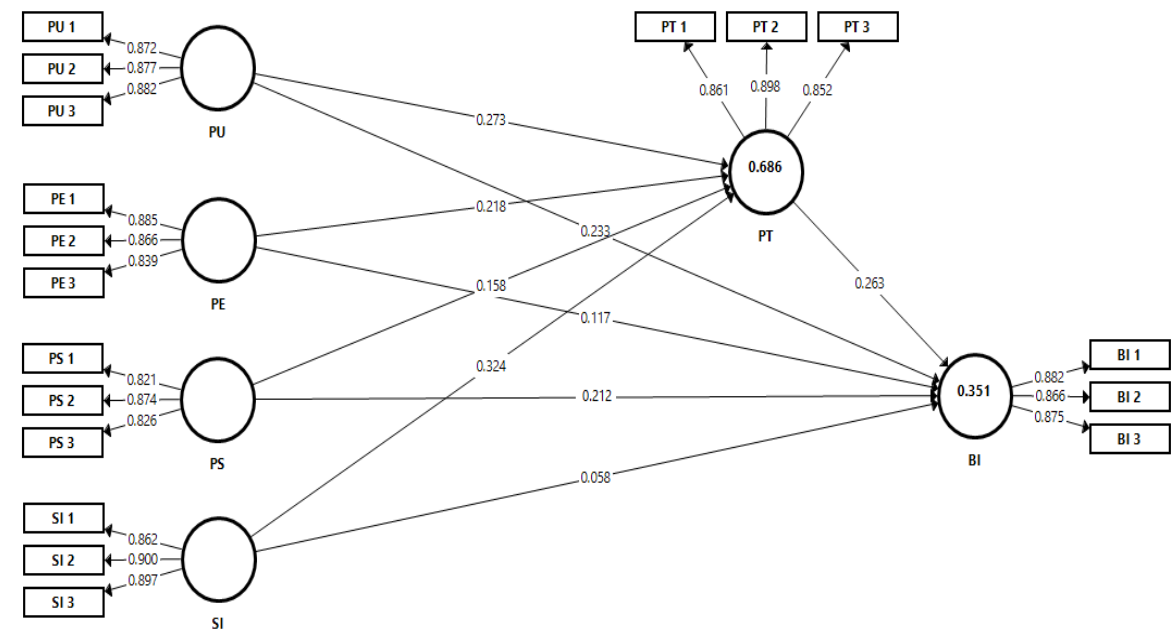

Fig. 1. Measurement Model

\subsubsection{Convergent Validity}

Table 1

The CFA Model's Convergent Validity

\begin{tabular}{|c|c|c|c|c|}
\hline Construct & Items & Factor loading & $\mathrm{CR}$ & AVE \\
\hline \multirow[t]{3}{*}{$\mathrm{PU}$} & PU 1 & 0.872 & \multirow[t]{3}{*}{0.909} & \multirow[t]{3}{*}{0.769} \\
\hline & PU 2 & 0.877 & & \\
\hline & PU 3 & 0.882 & & \\
\hline \multirow[t]{3}{*}{ PE } & PE 1 & 0.885 & \multirow[t]{3}{*}{0.898} & \multirow[t]{3}{*}{0.746} \\
\hline & PE 2 & 0.866 & & \\
\hline & PE 3 & 0.839 & & \\
\hline \multirow[t]{3}{*}{ PS } & PS 1 & 0.821 & \multirow[t]{3}{*}{0.879} & \multirow[t]{3}{*}{0.707} \\
\hline & PS 3 & 0.874 & & \\
\hline & PS 4 & 0.826 & & \\
\hline \multirow[t]{3}{*}{ SI } & SI 1 & 0.862 & \multirow[t]{3}{*}{0.917} & \multirow[t]{3}{*}{0.787} \\
\hline & SI 2 & 0.900 & & \\
\hline & SI 3 & 0.897 & & \\
\hline \multirow[t]{3}{*}{ PT } & PT 1 & 0.861 & \multirow[t]{3}{*}{0.904} & \multirow[t]{3}{*}{0.757} \\
\hline & PT 2 & 0.898 & & \\
\hline & PT 3 & 0.852 & & \\
\hline \multirow[t]{3}{*}{$\mathrm{BI}$} & BI 1 & 0.882 & \multirow[t]{3}{*}{0.907} & \multirow[t]{3}{*}{0.765} \\
\hline & BI 2 & 0.866 & & \\
\hline & BI 3 & 0.875 & & \\
\hline
\end{tabular}

Table 1 shows the confirmatory factor analysis for the measurement model. It is also possible to see the evaluation results of the model items' standardized factor loadings. The standardized factor loadings were all above the threshold of 0.5 and ranged between 0.821 and 0.900. Furthermore, the AVE values ranged from 0.879 to 0.919 for all constructs. According to Hair et 
al. (2019), the cut-off value was 0.5, and all values were more than this. The composite reliability values for all constructs ranged from 0.891 to 0.934 , which were all more than the suggested value of 0.7 for all constructs as described in (Hair et al, 2019).

\subsubsection{Discriminant validity}

In the present study, HTMT values were observed to identify the model's discriminant validity (Henseler, 2015; Ngah et al., 2021).

Table 2

The HTMT for constructs

\begin{tabular}{|c|c|c|c|c|c|c|}
\hline & $\mathrm{PU}$ & $\mathrm{PE}$ & PS & SI & PT & BI \\
\hline \multicolumn{7}{|l|}{$\mathrm{PU}$} \\
\hline PE & 0.641 & & & & & \\
\hline PS & 0.733 & 0.739 & & & & \\
\hline SI & 0.763 & 0.567 & 0.219 & & & \\
\hline PT & 0.432 & 0.409 & 0.603 & 0.733 & & \\
\hline BI & 0.398 & 0.761 & 0.551 & 0.812 & 0.600 & \\
\hline
\end{tabular}

Table 2 shows that the HTMT values for all constructs were less than 0.90 and ranged from 0.219 to 0.812 . As a result, each latent concept evaluation was totally discriminatory (Henseler et al., 2015). After assessing the convergent and discriminant validity of the measurement model, it was concluded that the measurement scale used to assess the components and their related items in the CFA model was completely reliable and valid.

\subsection{Hypothesis testing}

The findings of hypothesis testing were reported on the basis of the values of direct and indirect effects in the structural model (Fig. 1). These are presented in the following two subsections.

\subsubsection{Hypothesized direct effects of the constructs in structural model}

As can be noticed from table 3 , the $\mathrm{R}^{2}$ values for $\mathrm{PT}$ and $\mathrm{BI}$ are 0.686 and 0.351 , respectively. This reveals that the predictors (PU, PE, PS, SI) explain 68.6 percent of PT change and only 35.1 percent of BI variation. The R2 values meet the 0.19 cutoff value, according to the findings of (Chin, 1998). The BI Q2 value of 0.241 was significantly greater than zero, showing that the model had predictive validity, which is consistent with the recommendations of (Chin, 2010). The model has a high level of fit and predictive capability. Furthermore, the VIF values ranged from 1.147 to 3.467, which were all less than 5. (Hair, 2014. In predicting BI, the p-values of (PU, PE, PS, SI, and PT) were 0.052; 0.000; 0.000; and 0.003, respectively. The pvalues of PU, PE, PS, and SI for PT predictive factors were $0.061 ; 0.000 ; 0.002 ; 0.000$, indicating that the probability of predicting using absolute $\mathrm{p}$-values is between 0.01 and 0.05 . This demonstrates that the links are positive, and hypotheses $\mathrm{H} 2$, H3, H4, H6, H7, H8, and H9 are supported, but not H1, H5.

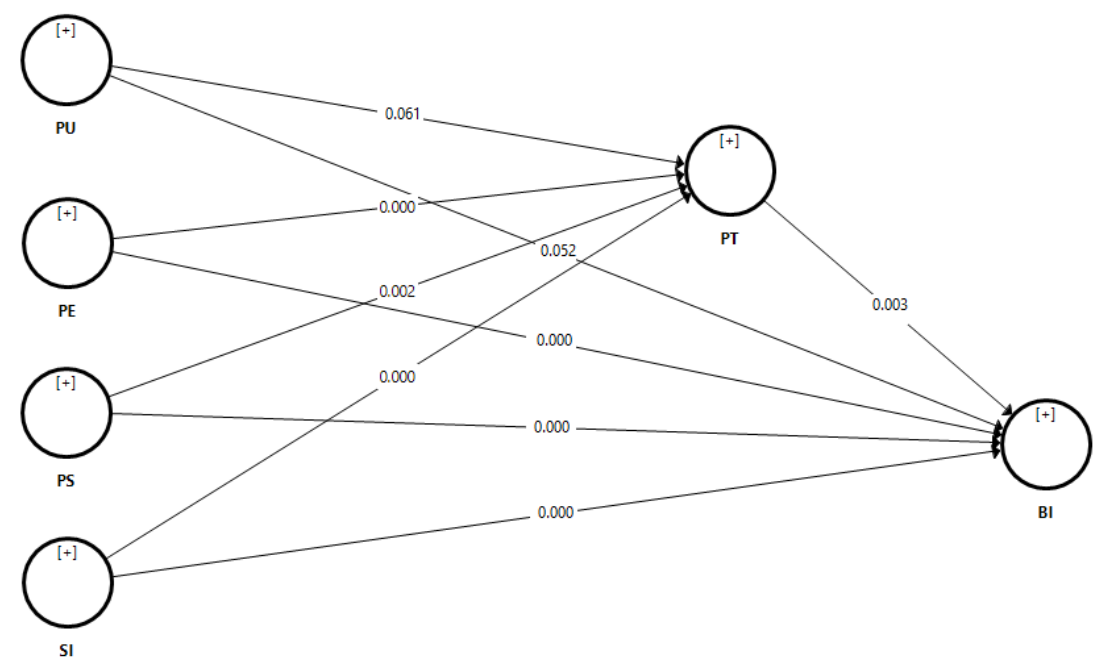

Fig. 2. Hypotheses Testing 
Table 3

Direct Effects

\begin{tabular}{lcccccccccccc}
\hline & PATH & St, $\beta$ & St. d & R $^{2}$ & $\mathrm{Q}^{2}$ & $\mathrm{~F}^{2}$ & VIF & T-value & P-value & Decision \\
\hline H1 & PU $\rightarrow$ BI & 0.233 & 0.056 & 0.686 & 0.241 & 0.051 & 3.467 & 4.160 & 0.052 & Not supported \\
H2 & PE $\rightarrow$ BI & 0.117 & 0.040 & & & 0.027 & 1.224 & 2.925 & 0.000 & Supported \\
H3 & PS $\rightarrow$ BI & 0.212 & 0.055 & & & 0.123 & 2.527 & 3.854 & 0.000 & Supported \\
H4 & SI $\rightarrow$ BI & 0.058 & 0.018 & & & 0.037 & 3.645 & 3.222 & 0.000 & Supported \\
H5 & PU $\rightarrow$ PT & 0.273 & 0.066 & 0.351 & & 0.119 & 3.467 & 4.136 & 0.061 & Not supported \\
H6 & PE $\rightarrow$ PT & 0.218 & 0.073 & & & 0.026 & 1.147 & 7.266 & 0.000 & Supported \\
H7 & PS $\rightarrow$ PT &.$\cdot 212$ & 0.075 & & & 0.057 & 2.340 & 2.826 & 0.002 & Supported \\
H8 & SI $\rightarrow$ PT & 0.324 & 0,095 & & & 0.029 & 3.035 & 0.341 & 0.000 & supported \\
H9 & PT $\rightarrow$ BI & 0.263 & 0.063 & & & 0.087 & 2.501 & 4.174 & 0.003 & Supported \\
\hline
\end{tabular}

\subsubsection{Mediation hypotheses}

From the Bootstrapping outcomes displayed in Table 5, there was an indirect effect of PT on the relationship between PE and $\mathrm{BI}$, and the relationship between PS and BI, and the relationship between PS and BI. The effect was significant at 0.05 level for all hypotheses were, $\beta=0.252, \mathrm{~T}$-value $=2.153, \mathrm{~T}$-value $=3.857$, P-value $=0.003$; T-value $=2.255, \mathrm{P}$-value $=0.032 ; \mathrm{T}$ value $=2.750, \mathrm{P}$-value $=0.006, \mathrm{~T}$-value $=2.090, \mathrm{P}$-value $=0.058 ;$ respectively. This means there is existing mediation because the p-values for all hypotheses less than 0.05 where were $0.003,0.032,0.006$ respectively, and the indirect effect of Boot CI Bias Corrected did not straddle a 0 in between, based on Preacher and Hayes (2004, 2008). And With exception to the indirect effect of PT on the relationship between PU and BI, because the p-value was 0.058 this clear it is more than 0.05 , and the indirect effect of Boot CI Bias straddled a 0 in between and based on Preacher and Hayes $(2004,2008)$, there is no mediation. As such, hypotheses H11, H12, and H13 were supported. but H10, not supported.

\section{Table 4}

Indirect Effects

\begin{tabular}{ccccccccc}
\hline & PATH & St. $\beta$ & St. d & T values & $2.50 \%$ & $97.50 \%$ & p-values & Decision \\
\hline H10 & PU $\rightarrow$ PT $\rightarrow$ BI & 0.232 & 0.111 & 2.090 & -0.030 & 0.0127 & 0.058 & Not supported \\
H11 & PE $\rightarrow$ PT $\rightarrow$ BI & 0.081 & 0.021 & 3.857 & 0.023 & 0.138 & 0.003 & Supported \\
H12 & PS $\rightarrow$ PT $\rightarrow$ BI & 0.097 & 0.043 & 2.255 & 0.022 & 0.109 & 0.032 & Supported \\
H13 & SI $\rightarrow$ PT $\rightarrow$ BI & 0.088 & 0.032 & 2.750 & -0.087 & -0.004 & 0.006 & Supported \\
\hline
\end{tabular}

\section{Discussion}

The main objective of this study was to investigate the determinants of behavioral intentions to the use of mobile health (mHealth) applications in Jordan through examining the mediating role of perceived trust and its influence on the behavioral intention to use such applications. PLS 3.3.3 was utilized to examine the thirteen study hypotheses proposed in this research. Results indicated that most of the hypotheses were supported. The first hypothesis (H1) relating PU on the behavioral intentions to use m-Health applications was not supported. While the second hypothesis (H2) relating PEOU on behavioral intention to use m-Health applications was supported. PEOU were found to be a significant predictor of patients' intention to use $\mathrm{m}$-Health applications. This conforms to the findings of previous empirical studies reported in the literature (Holden \& Karsh, 2010; Phan \& Daim, 2011; Sintonen \& Immonen 2013). Many studies indicate that PEOU significantly influences patients' intention to use m-Health applications (Fagih and Jaradat, 2015; Zhao et al., 2017; ALsswey et al., 2018). Our results support the third hypothesis (H3). Such findings revealed that SU affects patients' intention to use m-Health applications. This result is in line with previous research findings; several studies in m-Health have indicated that social influence has a significant effect on the intention to use m-Health applications (Zhang et al., 2014; Miao et al., 2017; Aljohani \& Chandran, 2019). Moreover, the fourth hypothesis (H4) relating PS to behavioral intention to use m-Health applications was supported. This indicates that whenever patients' feel that their data is safe and protected, they will be more into using m-Health applications. This result is in the same vein with Several studies have acknowledged that security issues are significantly critical for the acceptance and wide use of m-Health technologies (Sun et al., 2010; Fernandez-Aleman et al., 2013; Alloghani et al., 2015; Petersen et al., 2020).

Further, H5 which relates PU on PT was not supported, while the results of our study support hypotheses (H6-H8) relating to PEOU, SI and PS on the PT. These results are in line with previous studies conducted by Damghanian et al (2016), LiébanaCabanillas et al. (2014) and Ventre and Kolbe (2020). Moreover, the ninth hypothesis (H9) relating PT to behavioral intention to use m-Health applications was supported. This indicates that patients will use m-Health applications only if they are assured that these applications will function properly and will deliver accurate and reliable information. This result is in line with a recent study by Li (2020) who found that trust can significantly influence patients' attitude towards using m-Health services. Finally, the mediating impact of perceived trust on patients' intention to use m-Health applications was also supported except for H10. Therefore, hypotheses (H11-H13) were supported. Such results support the findings of Yoon (2009) and Shareef (2011) who claimed that trust has a direct or indirect mediation effect on users' intention to adopt or use new technology. It is also in line with the findings of Al-Sharafi et al., (2017) who found that trust plays a mediator role between PU and users' intentions. 


\section{Conclusions and Contribution}

The results of this research show the importance of PEOU, PS, SI and PT as strong constructs in forming patients' perceptions and driving their behavioral intentions towards utilizing $\mathrm{m}$-Health applications. Moreover, PT plays a vital role on patients' behavioral intentions, suggesting that trust is a critical factor in the relationship between patients and the use of $\mathrm{m}$-Health applications. As such, once the patient perceives the m-Health application as a trustable source, he/she will develop a more favorable attitude towards using this application. The research findings boost the existing literature on the influence of different factors including PU, PEOU, SI, PS and PT on patients' behavioral intention to use m-Health applications in developing countries such as Jordan. Thus, the study's findings provide a comprehensive understanding about the role of PT in the acceptance of m-Health applications. Empirically, this research provides valuable insights into how the PT can be utilized to enhance the acceptance and spread the use of m-Health applications. The findings of this research also bear several important practical implications. Firms are required to be aware of the significant role of PEOU, SI, PS and PT in forming patients' favorable perceptions and boosting their tendency to use m-Health applications. Therefore, practitioners have to pay attention to many features in their m-Health applications including ease of use, social influence, security and trust in order to promote their applications. Enhancing these features in m-Health applications will significantly impact patients' behavioral intentions.

\section{Limitations and future research recommendations}

This research suffered from some limitations, especially sampling producers and sampling size, which affect the generalizability of the findings. However, such limitations could be avoided in the future by applying probability sampling techniques to recruit respondents, to generate more reliable and generalizable findings. Further, this research can be extended to consider the moderating role of demographic factors to understand patients' intention to use m-Health applications based on their demographics like age, gender, and educational level.

\section{References}

Akter, S., Ray, P., \& D'Ambra, J. (2013). Continuance of mHealth services at the bottom of the pyramid: the roles of service quality and trust. Electronic Markets, 23(1), 29-47.

Al-Gasawneh, J. A., \& Al-Adamat, A. M. (2020). The relationship between perceived destination image, social media interaction and travel intentions relating to Neom city. Academy of Strategic Management Journal, 19(2), 1-12.

Al-Gasawneh, J., Al-Wadi, M., Al-Wadi, B., Alown, B. \& Nuseirat, N. (2020). The Interaction Effect of Comprehensiveness Between social media and Online Purchasing Intention in Jordanian Pharmacies. International Association of Online Engineering. Retrieved july 13, 2020 from https://www.learntechlib.org/p/217794/.

Al-Hazmi, N. M. (2021). The Use of Mobile Phones and their Apps in Tourism Marketing in the Kingdom of Saudi Arabia. International Journal of Interactive Mobile Technologies, 15(6).

Aljohani, N., \& Chandran, D. (2019). Adoption of M-Health Applications: The Saudi Arabian Healthcare Perspectives.

Alloghani, M., Hussain, A., Al-Jumeily, D., \& Abuelma'atti, O. (2015, December). Technology Acceptance Model for the Use of M-Health Services among health related users in UAE. In 2015 International Conference on Developments of ESystems Engineering (DeSE) (pp. 213-217). IEEE.

Alsajjan, B., \& Dennis, C. (2010). Internet banking acceptance model: Cross-market examination. Journal of business research, 63(9-10), 957-963.

Al-Sharafi, M. A., Arshah, R. A., Herzallah, F. A., \& Alajmi, Q. (2017). The effect of perceived ease of use and usefulness on customers intention to use online banking services: the mediating role of perceived trust. International Journal of Innovative Computing, 7(1).

ALsswey, A., Naufal, I., \& Bervell, B. (2018). Investigating the acceptance of mobile health application user interface cultural-based design to assist Arab elderly users. International Journal of Advanced Computer Science and Applications, 9(8), 144-152.

Amin, M., Rezaei, S., \& Abolghasemi, M. (2014). User satisfaction with mobile websites: the impact of perceived usefulness (PU), perceived ease of use (PEOU) and trust. Nankai Business Review International.

Baek, S., Seo, S. H., \& Kim, S. (2016). Preserving patient's anonymity for mobile healthcare system in IoT environment. International Journal of Distributed Sensor Networks, 12(7), 2171642.

Baig, M. M., GholamHosseini, H., \& Connolly, M. J. (2015). Mobile healthcare applications: system design review, critical issues and challenges. Australasian Physical \& eEngineering sciences in medicine, 38(1), 23-38.

Bolarinwa, O. A. (2015). Principles and methods of validity and reliability testing of questionnaires used in social and health science researches. Nigerian Postgraduate Medical Journal, 22(4), 195

Carmi, L., Zohar, J., Arush, O. B., \& Morein-Zamir, S. (2020). From checking the door to checking the app: assessment and treatment implications for obsessive-compulsive disorder in the digital era. CNS spectrums, 1-2.

Chin, W. W. (1998). Commentary: Issues and opinion on structural equation modeling.

Chin, W. W. (2010). How to write up and report PLS analyses. In Handbook of partial least squares (pp. 655-690). Springer, Berlin, Heidelberg.

Damghanian, H., Zarei, A., \& Siahsarani Kojuri, M. A. (2016). Impact of perceived security on trust, perceived risk, and acceptance of online banking in Iran. Journal of Internet Commerce, 15(3), 214-238. 
Dunnewijk, T., \& Hultén, S. (2007). A brief history of mobile communication in Europe. Telematics and Informatics, 24(3), 164-179.

Eze, E., Gleasure, R., \& Heavin, C. (2020). Mobile health solutions in developing countries: a stakeholder perspective. Health Systems, 9(3), 179-201.

Gefen, D., Rigdon, E. E., \& Straub, D. (2011). Editor's comments: an update and extension to SEM guidelines for administrative and social science research. Mis Quarterly, iii-xiv.

Green, S. B. (1991). How many subjects does it take to do a regression analysis. Multivariate behavioral research, 26(3), 499-510.

Hair, J. F., \& Risher, J. J. MS and CMR (2019). When to use and how to report the results of PLSSEM", European Business Review, 31(1), 2-24.

Hammouri, Q. M., Abu-Shanab, E. A., \& Nusairat, N. M. (2021a). Attitudes Toward Implementing E-Government in Health Insurance Administration. International Journal of Electronic Government Research (IJEGR), 17(2), 1-18.

Hammouri, Q., \& Abu-Shanab, E. (2017, May). The antecedents of trust in social commerce. In 2017 8th International Conference on Information Technology (ICIT) (pp. 648-652). IEEE.

Hammouri, Q., \& Abu-Shanab, E. A. (2020). Major Factors Influencing the Adoption of Cloud Computing in Jordan. International Journal of Technology and Human Interaction (IJTHI), 16(4), 55-69.

Hammouri, Q., Al-Gasawneh, J. A., Nusairat, N. M., Hanandeh, A., \& Barakat, S. (2021b). The Determinants of Trust and its Influence on Online Buying Intention: An Empirical Study on Social Commerce in Jordan. Annals of the Romanian Society for Cell Biology, 4522-4539.

Hammouri, Q., Almajali, D. A., Nusairat, N., \& Saraireh, S. (2020). Determinants of Users' Satisfaction withMobile Apps. International Journal of Advanced Science and Technology, 29(3), 14613-14624.

Hawamleh, A. M. A., Alorfi, A. S. M., Al-Gasawneh, J. A., \& Al-Rawashdeh, G. (2020). Cyber Security and Ethical Hacking: The Importance of Protecting User Data. Solid State Technology, 63(5), 7894-7899.

Henseler, J., Ringle, C. M., \& Sarstedt, M. (2015). A new criterion for assessing discriminant validity in variance-based structural equation modeling. Journal of the academy of marketing science, 43(1), 115-135.

Hoque, M. R., \& Bao, Y. (2015). Cultural influence on adoption and use of e-Health: evidence in Bangladesh. Telemedicine and e-Health, 21(10), 845-851.

Istepanian, R. S., \& AlAnzi, T. (2020). Mobile health (m-health): Evidence-based progress or scientific retrogression. In Biomedical Information Technology (pp. 717-733). Academic Press.

Latif, S., Rana, R., Qadir, J., Ali, A., Imran, M. A., \& Younis, M. S. (2017). Mobile health in the developing world: Review of literature and lessons from a case study. IEEE Access, 5, 11540-11556.

Laxminarayan, S., \& Istepanian, R. S. (2000). UNWIRED E-MED: the next generation of wireless and internet telemedicine systems. IEEE Transactions on Information Technology in Biomedicine, 4(3), 189-193.

Lee, C., Lee, K., \& Lee, D. (2017). Mobile healthcare applications and gamification for sustained health maintenance. Sustainability, 9(5), 772.

Lee, C. C., Hsu, C. W., Lai, Y. M., \& Vasilakos, A. (2013). An enhanced mobile-healthcare emergency system based on extended chaotic maps. Journal of medical systems, 37(5), 1-12.

Lee, T., \& Jun, J. (2007). Contextual perceived value? Investigating the role of contextual marketing for customer relationship management in a mobile commerce context. Business Process Management Journal.

Li, Q. (2020). Healthcare at your fingertips: The acceptance and adoption of mobile medical treatment services among chinese users. International journal of environmental research and public health, 17(18), 6895.

Liébana-Cabanillas, F., Sánchez-Fernández, J., \& Muñoz-Leiva, F. (2014). Antecedents of the adoption of the new mobile payment systems: The moderating effect of age. Computers in Human Behavior, 35, 464-478.

Lupieri, S., \& Frisina Doetter, L. (2020). Transnational interdependency and healthcare system change: The role of humanitarian and development aid in shaping health policy in Jordan. Global Social Policy, 20(2), 192-214.

Manyati, T. K., \& Mutsau, M. (2021). A systematic review of the factors that hinder the scale up of mobile health technologies in antenatal care programmes in sub-Saharan Africa. African Journal of Science, Technology, Innovation and Development, 13(1), 125-131.

Mcknight, D. H., Carter, M., Thatcher, J. B., \& Clay, P. F. (2011). Trust in a specific technology: An investigation of its components and measures. ACM Transactions on management information systems (TMIS), 2(2), 1-25.

Meshram, C., Lee, C. C., Meshram, S. G., Ramteke, R. J., \& Meshram, A. (2020). An efficient mobile-healthcare emergency framework. Journal of medical systems, 44(3), 1-14.

Miao, R., Wu, Q., Wang, Z., Zhang, X., Song, Y., Zhang, H., ... \& Jiang, Z. (2017). Factors that influence users' adoption intention of mobile health: a structural equation modeling approach. International Journal of Production Research, 55(19), 5801-5815.

Mohamed, A. H. H., Tawfik, H., Al-Jumeily, D., \& Norton, L. (2011, December). MoHTAM: A technology acceptance model for mobile health applications. In 2011 Developments in E-systems Engineering (pp. 13-18). IEEE.

Ngah, A. H., Gabarre, S., Han, H., Rahi, S., Al-Gasawneh, J. A., \& Park, S. H. (2021). Intention to purchase halal cosmetics: do males and females differ? A multigroup analysis. Cosmetics, 8(1), 19.

Nusairat, N., Al-Gasawneh, J., Aloqool, A., Alzubi, K., Akhorshaideh, A., Joudeh, J., \& Ibrahim, H. (2021). The relationship between Internet of things and search engine optimization in Jordanian Tele-Communication Companies: The mediating role of user behavior. International Journal of Data and Network Science, 5(3), 163-172. 
Nusairat, N. M., Hammouri, Q., Al-Ghadir, H., Ahmad, A. M. K., \& Abuhashesh, M. (2020a). Fitness Centers AmbienceCustomer Behavioral Intentions Relationship: The Mediating Role of Customer Emotional States. International Journal of Business and Management, 15(9).

Nusairat, N., Hammouri, Q., Al-Ghadir, H., Ahmad, A., \& Eid, M. (2020b). The effect of design of restaurant on customer behavioral intentions. Management Science Letters, 10(9), 1929-1938.

Petersen, F., Jacobs, M., \& Pather, S. (2020). Barriers for user acceptance of mobile health applications for diabetic patients: Applying the utaut model. Responsible design, implementation and use of information and communication technology, 12067, 61 .

Puriwat, W., \& Tripopsakul, S. (2017). Mobile banking adoption in Thailand: an integration of technology acceptance model and mobile service quality.

Qureshi, K. N., Din, S., Jeon, G., \& Piccialli, F. (2020). An accurate and dynamic predictive model for a smart M-Health system using machine learning. Information Sciences, 538, 486-502.

Schaefer, K. E., Chen, J. Y., Szalma, J. L., \& Hancock, P. A. (2016). A meta-analysis of factors influencing the development of trust in automation: Implications for understanding autonomy in future systems. Human factors, 58(3), 377-400.

Shareef, M. A., Kumar, V., Kumar, U., \& Dwivedi, Y. K. (2011). e-Government Adoption Model (GAM): Differing service maturity levels. Government information quarterly, 28(1), 17-35.

Sintonen, S., \& Immonen, M. (2013). Telecare services for aging people: Assessment of critical factors influencing the adoption intention. Computers in Human Behavior, 29(4), 1307-1317.

Tachakra, S., Wang, X. H., Istepanian, R. S., \& Song, Y. H. (2003). Mobile e-health: the unwired evolution of telemedicine. Telemedicine Journal and E-health, 9(3), 247-257.

Venkatesh, V., Thong, J. Y., \& Xu, X. (2012). Consumer acceptance and use of information technology: extending the unified theory of acceptance and use of technology. MIS quarterly, 157-178.

Ventre, I., \& Kolbe, D. (2020). The impact of perceived usefulness of online reviews, trust and perceived risk on online purchase intention in emerging markets: A Mexican perspective. Journal of International Consumer Marketing, 32(4), 287-299.

Yang, X., \& Kovarik, C. L. (2021). A systematic review of mobile health interventions in China: identifying gaps in care. Journal of telemedicine and telecare, 27(1), 3-22.

Yoon, C. (2009). The effects of national culture values on consumer acceptance of e-commerce: Online shoppers in China. Information \& Management, 46(5), 294-301.

Zhang, T., Tao, D., Qu, X., Zhang, X., Zeng, J., Zhu, H., \& Zhu, H. (2020). Automated vehicle acceptance in China: Social influence and initial trust are key determinants. Transportation research part C: emerging technologies, 112, $220-233$.

Zhang, X., Guo, X., Lai, K. H., Guo, F., \& Li, C. (2014). Understanding gender differences in m-health adoption: a modified theory of reasoned action model. Telemedicine and e-Health, 20(1), 39-46.

Zhao, Y., Ni, Q., \& Zhou, R. (2018). What factors influence the mobile health service adoption? A meta-analysis and the moderating role of age. International Journal of Information Management, 43, 342-350. 
(C) 2021 by the authors; licensee Growing Science, Canada. This is an open access article distributed under the terms and conditions of the Creative Commons Attribution (CC-BY) license (http://creativecommons.org/licenses/by/4.0/). 